\title{
ACUTE BRADYCARDIA AND ATELECTASIS AFTER ENDOTRACHEAL INTUBATION IN CLEFT CHILD: A CASE REPORT AND REVIEW OF ANESTHESIA MANAGEMENT IN CLEFT LIP AND PALATE PATIENTS
}

\section{SWETHA K ${ }^{1 *}$, SAI PRIYANKA K ${ }^{2}$}

${ }^{1}$ Department of Oral and Maxillofacial Surgery, Lotus Hospital for Children and Women, Hyderabad, Telangana, India. ${ }^{2}$ Department of Oral Periodontology and Implantology, Lotus Hospital for Children and Women, Hyderabad, Telangana, India. Email: drswetha99@gmail.com

Received: 13 September 2019, Revised and Accepted: 16 October 2019

\section{ABSTRACT}

The most common craniofacial anomalies in children are cleft lip and palate with an incidence of 1:800 live births. Associated anomalies are common in patients with both cleft lip and palate (28\%). Most commonly these anomalies affect the vertebral column or limb (33\%) and the cardiovascular system (24\%). Almost 150 syndromes are associated with cleft deformities and well known are Pierre Robin's, Goldenhar, and Treacher Collins syndrome. On an average, 5-10\% of these patients have congenital heart disease (CHD) such as ventricular septal defect, atrial septal defect, and cyanotic CHD. Until now, there are no clear guidelines regarding the timing of cleft surgery, especially if the child is having airway problems. In this article, we report an unusual case of a 6-month-old female child with weight of $6.5 \mathrm{~kg}$ with no medical history, who underwent surgical repair of congenital cleft lip in general anesthesia, leading to sudden collapse.

Keywords: Anesthesia, Cleft lip, Airway obstruction, Complications, Endotracheal intubation, Airway management

(C) 2019 The Authors. Published by Innovare Academic Sciences Pvt Ltd. This is an open access article under the CC BY license (http://creativecommons. org/licenses/by/4. 0/) DOI: http://dx.doi.org/10.22159/ajpcr.2019.v12i11.35671

\section{INTRODUCTION}

Cleft lip and palate are the defects of birth caused by the disorder of anatomical and genetical factors [1]. The fundamental aspect of anesthetic practice is an airway management. The rapid, simple, and non-surgical technique of airway management is endotracheal intubation (ETI), which protects lungs from aspiration, maintains airway patency, and permits leak-free ventilation. Laryngeal mask airway (LMA) and combitube are alternatives to ETI, where ETI is difficult in performing or has failed. Complications which can also be life threatening are associated with both ETI and other airways. Anesthesiologists must be aware of such complications and must have a strategy to effectively manage and prevent such complications. In pediatric anesthesia, especially in cleft patients, airway-related problems account for majority of anesthetic morbidity and mortality. The success of cleft repair depends on associated anomalies, patient's age at the time of surgery, expertise of anesthetist, and post-operative care [2]

\section{CASE REPORT}

A 6-month-old female child in Fig. 1 weighing $6.5 \mathrm{~kg}$ who had congenital cleft lip and palate was admitted in children's hospital for the cleft lip repair. Informed written consent form was obtained from the parents. Routine blood investigations (complete blood picture, random blood sugar, serum creatinine, blood grouping, clotting time, bleeding time, human immunodeficiency virus I and II, and hepatitis B surface antigen) were done. Chest X-ray and pediatrician consent for surgery under general anesthesia were obtained before surgery. Pre-operative fasting was observed for $4 \mathrm{~h}$ for milk and $2 \mathrm{~h}$ for clear fluids. Baseline vital parameters such as heart rate, non-invasive blood pressure, electrocardiogram, and peripheral capillary oxygen saturation $\left(\mathrm{SpO}_{2}\right)$ were noted inside the operation theater.

General anesthesia was infused with intravenous (IV) induction. Premedication with IV antibiotic, glycopyrrolate $0.004 \mathrm{mg} / \mathrm{kg}$, midazolam $0.05 \mathrm{mg} / \mathrm{kg}$, and tramadol $1 \mathrm{mg} / \mathrm{kg}$ was given and induced with propofol $1.5 \mathrm{mg} / \mathrm{kg}$. ET tube of size 3.5 number uncuffed south pole Ring-Adair-Elwyn (RAE) tube was placed. After mask ventilation, rocuronium $0.8 \mathrm{mg} / \mathrm{kg}$, IV was given and maintained with halothane
$0.4-1 \%$ in $50 \% \mathrm{~N}_{2} \mathrm{O}$ in oxygen. After few minutes of intubation, there were sudden bradycardia and desaturation (fall in oxygen saturation $<60$ ) and did not respond with administration of $100 \%$ oxygen, injection of atropine $0.01 \mathrm{mg} / \mathrm{kg} \mathrm{IV}$, and hydrocortisone. On auscultation, chest sounds were not clear on the left side. The patient was immediately shifted to higher center for better management.

On admission at a higher center, the baby had depressed sensorium and seizures. Infant was connected to Synchronised Intermittend mandatoryl ventilator (SIMV). The baby was started with normal saline bolus, given IV fluid antibiotics and other supportive measures. Arterial blood gases (ABG) showed respiratory acidosis. Inotropic (dopamine dobutamine) support was started in view of poor perfusion. Seizures were controlled with IV lorazepam + IV levipil, IV phenobarbital, and midazolam infusion.

Initial chest X-ray showed the left lung collapse which can be shown in Fig. 2 with ET tube placed low down toward the right main bronchus which was pulled back and repositioned. Repeat chest X-ray showed good expansion of the left lung (Fig. 3). Repeat ABG was normal, neurosonography was normal, and electroencephalogram was abnormal showing epileptiform discharges. Pediatric neurologist consultation was taken who advised to continue same treatment and plan to do magnetic resonance imaging brain later on to ascertain the central nervous system insult possibly due to hypoxia. Anticonvulsants were slowly tapered and stopped gradually (Midazolam drip + gardenal). The baby gradually improved with treatment and sensorium improved, and hence, the infant was extubated after 2 days and put on oxygen with nasal prongs. Ryle's tube feeds were started. The child had tachypnea and occasional cough.

With the treatment, sensorium was better and had no seizures. Oxygen was weaned off and full oral feeds were established. The baby was hemodynamically stable after 3 days at the time of discharge.

\section{DISCUSSION}

Anesthesia for patients with cleft lip and palate requires ETI for the maintenance of clear and patent airway for easy surgical access. Head- 


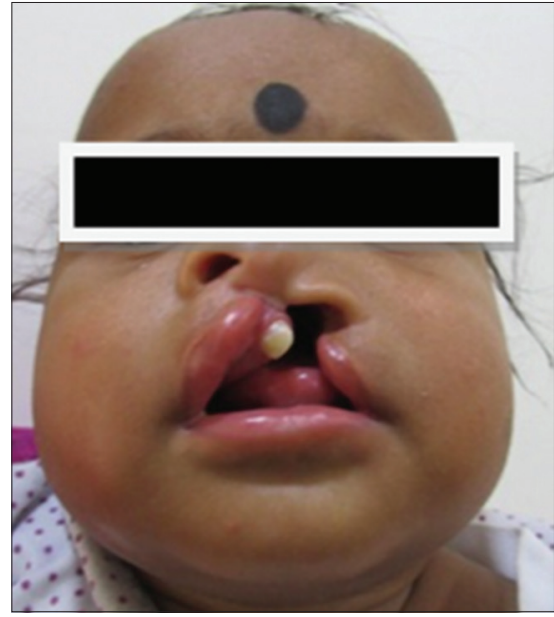

Fig. 1: A 6-month-old female child

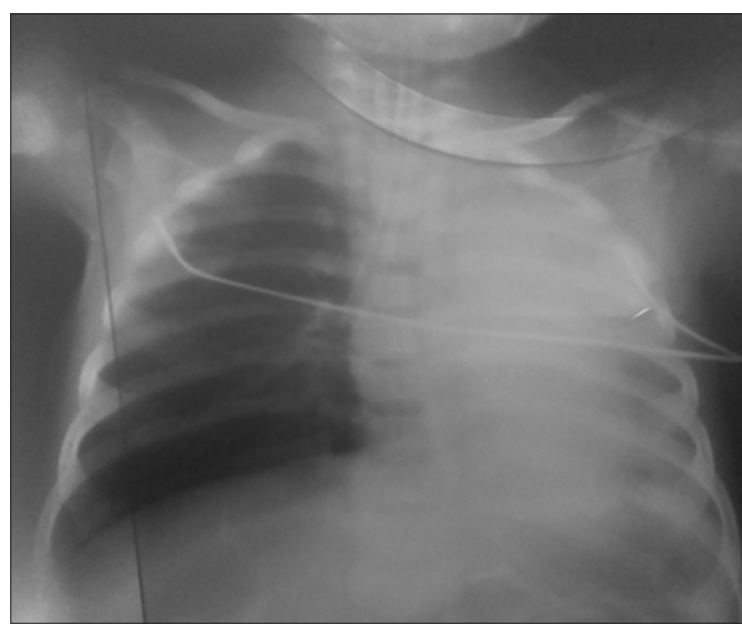

Fig. 2: Collapsed left lung

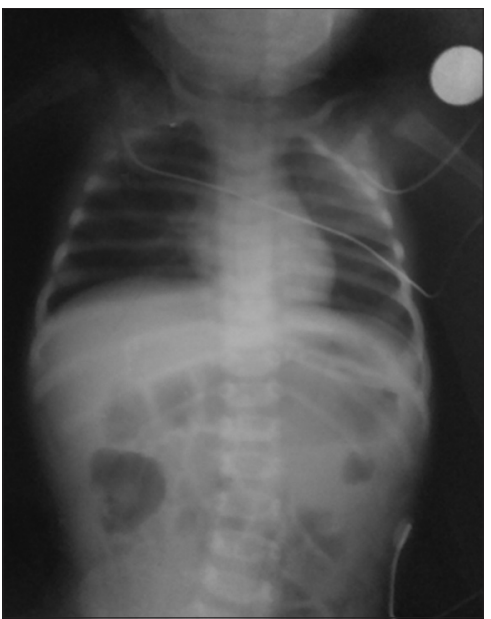

Fig. 3: Reinflated lung

and-neck anomalies associated with syndromes can create difficulties with ETI and airway maintenance which can vary from mild to extreme [3,4]. The anesthetist must be familiar with these anatomical and physiological disturbances if optimal outcomes are to be achieved. Magill almost a century ago was the first to recognize problems with airway management in children with cleft lip and palate [4].
Pre-operative evaluation

Children with cleft deformities are usually associated with hearing defects, upper respiratory tract, and ear infections and also have poor nutrition and anemia. Anemia can be corrected by oral iron therapy. However, literature suggests that a mild degree of anemia [hemoglobin 8-10 G/dl] does not increase perioperative complications [5]. In children with cleft lip and palate, chronic nasal and sinus infections are common and predispose to upper and lower respiratory tract infections and ear disease. Post-operative respiratory complications are higher in patients with respiratory tract infections [6]. It is better to postpone surgery if the patient is having respiratory tract infection in pre-operative evaluation. Check for the presence of syndrome and associated condition which may affect the course of anesthesia. The head-and-neck syndromes involving branchial arch development are difficult to intubate.

Atlantoaxial subluxation in Down's syndrome makes neck extension risky and hence before intubation, X-ray neck with special emphasis on the atlantoaxial joint is advisable to rule out atlantoaxial ligament laxity. Down's syndrome patients with unstable cervical spine should be carefully positioned to prevent neurologic damage. In an asymptomatic Down's syndrome patient, where cervical spine radiography is not done, head and neck should be kept in a neutral position intraoperatively. Todd et al. [7] reported that patients who are neurologically intact with normal neck radiographs do not appear to be at high risk with up to $60^{\circ}$ neck rotation. In Klippel Feil syndrome patients, the limitation of head movements and abnormal cervical spine makes intubation difficult. Hence, all patients should be thoroughly examined to assess any such conditions. Infants and children are more prone to airway edema due to relatively small trachea and larynx. Hypoxic events are also more common in patients with difficult airway.

Size and movements of tongue as well as neck, shape and size of mandible, and extent of mouth opening should be examined. The previous anesthesia experience must be recorded but ease of intubation changes with age in few cases. For example, it is easy to intubate for isolated cleft palate patients as they grow older [8] and it is difficult for patients with Goldenhar syndrome as age advances. Atlanto-occipital joint extension, Mallampati test, Wilson score, and Lemon score [9] are used for airway assessment in adults. As most of the children are uncooperative, Mallampati scoring is not reliable, especially in very young children. Cormack and Lehane in 1984 described the airway using four structures for identification which can be used for both children and adults. Cormack and Lehane laryngoscopic views classify airway as Grade I visualization of entire laryngeal aperture, Grade II posterior portion of laryngeal aperture is visible, Grade III only the epiglottis is visible, and Grade IV visualization of hard palate only [10]. In a study of 800 cleft lip/palate repair, Gunawardhana reports difficult intubation in $86 \%$ of cases and needs for external laryngeal pressure with Cormack and Lehane Grade III and IV airway grades. The incidence of difficult laryngoscopy was $34.6 \%$ in retrognathia, $45.7 \%$ in bilateral cleft lip, and $2.95 \%$ in unilateral. About $99 \%$ of patients had successful tracheal intubation in whom laryngoscopy was difficult. Pre-operative assessment of difficult intubation is not always possible.

Cyanosis, murmurs, and small stature if present, cardiologist assessment is required. Prophylactic antibiotics are necessary for children with congenital heart disease. Risk of subacute bacterial endocarditis is high in patients with cyanotic heart disease, prosthetic valves, and surgical shunts. Bilateral club foot increases the likelihood of cardiac and renal anomalies. Infants with bilateral club foot, cleft palate, myopathic facies, and myopathy resulting in delayed milestones are at risk of developing rigidity and hypercarbia which are signs of malignant hyperthermia [11].

\section{Induction of anesthesia}

Accidental tissue damage during intubation can be prevented by packing the cleft with moist gauze bandage. Premedication with atropine decreases secretions and laryngeal spasm and facilitate laryngoscopy. If it is suspected that airway is difficult, oral atropine 
$0.02 \mathrm{mg} / \mathrm{kg}$ (maximum dose $0.6 \mathrm{mg}$ ) can be given $45 \mathrm{~min}$ before induction. Midazolam $0.5-0.75 \mathrm{mg} / \mathrm{kg}$ orally can be given for children who are anxious.

Induction of anesthesia by inhalation should be given to children for whom it may be difficult to intubate. Xue et al. [12] reported that the use of muscle relaxants and analgesia reduces the incidence of difficult laryngoscopy. Gunawardana [8] avoided muscle relaxants till the airway is secured and had higher incidence of difficult laryngoscopy. Sevoflurane is widely used now for inhalation. Nitrous oxide helps to speed the induction. Propofol or thiopental followed by muscle relaxant can be given as IV induction for patients without airway problems. Oral preformed RAE ET tubes which will fit under the tongue plate of mouth gag during palate repair should be used for intubation.

If there is any possibility of cervical spine instability like in Nager syndrome or Down's syndrome, extreme caution must be taken during laryngoscopy and positioning. Bilateral lung ventilation should be done to ensure the correct placement of ET tube. Remember that, the tip of the ET tube will advance into bronchus if the head is flexed so much after intubation, if the head is extended tube will be withdrawn and leak may occur especially, if the tube has a Murphy eye [13].

Ventilation should be monitored carefully while placing mouth gag, ET tube may become displaced or kinked under the mouth gag if not placed properly. LMA should be used immediately if difficulty with ventilation occurs. Volatile anesthetic agents or IV drugs [14] can be used to maintain anesthesia; however, the procedure should allow the patient to awaken rapidly.

Propofol and sevoflurane infusion are compared for cleft palate repair in infants, patients receiving propofol anesthesia had high blood pressure and bradycardia [15], but the extubation time is shorter and had no significant post-operative difference. Hypercapnia which results in vasodilation and increased blood loss during cleft palate repair can be prevented by controlled ventilation. Inducing systemic hypotension to minimize blood loss is advisable during extensive procedures like Lefort I advancement. Mouth gag occasionally results in swelling of uvula or tongue [16], especially seen in Pierre Robin syndrome [17] patients. In such cases, the patient should be shifted to intensive care unit and extubation should be deferred until swelling subsides.

Flemming classified complications of ETI as minor trauma which is of lesser significance and those which should be immediately recognized and treated [18]. In our present case, complication might have raised due to endobronchial intubation which must be immediately recognized and managed. If a long tube is inserted into one of the main stem bronchi, endobronchial intubation occurs. Radiographically tube should be $3 \mathrm{~cm}$ above the carina and should be below the thoracic inlet. Rise and fall of chest wall with ventilations, adequate oxygen saturation $(>90 \%)$, and auscultation of breath sounds in both axillae and not over abdomen indicate correct position of ET tube in airway. If ET tube is misplaced into the right bronchus or esophagus immediately it should be removed and adequate ventilation must be given to patient.

In bronchial intubation, Gaseous exchange does not occur in the unintubated lung and will result in hypoxia as great volumes of blood which flows through this lung results in substantial right to left shunt. In addition, hyperinflation of intubated lung receiving whole tidal volume leads to barotrauma and hyperdistension [19]. Cyanosis and labored breathing are signs of arterial hypoxemia. Endobronchial intubation also results in light plane of anesthesia as uptake of inhalational anesthetic agent will impair. Asymmetric auscultation and asymmetric elevation of thorax are signs of deviation of ET tube into main bronchus. The ET tube should be withdrawn and lungs should be inflated to expand atelectatic areas when endobronchial intubation is discovered. Anesthesiologist must be careful while withdrawing tube which is in difficult or in awkward positions. Sometimes, repositioning of the patient and head movement may also result in misplacement of tube. Correct placement of ET tube should be confirmed before starting the surgical procedure, if there is any doubt regarding the correct placement of tube, tube should be withdrawn and can be reintroduced later.

Endobronchial intubation can also occur with south-facing RAE tubes which are most widely used for ET intubation. These tubes have a preformed "knee" which can be too long for infant leading to endobronchial intubation. To overcome this problem, "Knee" should be fixed on the mandible. In the present case, bradycardia during intubation may be due to hypoxia, caused by medication used for analgesia and sedation, and may also by laryngeal-vagal reflux, which is more common in infants below 2 years [20]. When cleft palate is repaired, infant's airway may become smaller than before. Reasons included are infant fails to adequately hold the tongue forward due to sedation and large ET tube resulting in laryngeal edema and stridor.

Extubation should be done only when infant is fully awake and after having full control of his airway reflexes. Pierre Robin syndrome patients have the risk of post-operative airway obstruction [21], if problem arises, the patient should be reintubated in the operating room. In many centers to ensure a good airway in the early post-operative period, surgeons place a long suture in the anterior tongue to pull the tongue forward. Superior pharyngeal flap operations or sphincter pharyngoplasty can result in hypoxia in the recovery room [22] and in some cases, death [23] can occur due to acute airway obstruction. Hence, continuous monitoring of oxygen saturation $\left(\mathrm{SpO}_{2}\right)$ should be done and should rapidly intervene if any such problem arises. Nasopharyngeal airway is inserted and left in situ after immediate post-operative period is advised. Merry et al. [24] recommended international standards for safe practice of anesthesia while performing cleft surgeries.

\section{CONCLUSION}

The technical skill, knowledge, and capability to manage crisis of an anesthesiologist play an important role in the occurrence and outcome of airway management and complications. Proper evaluation of patient and airway without hurried intubation prevents most of the complications.

\section{AUTHORS' CONTRIBUTIONS}

All authors have equally contributed for making this case report to be successful.

\section{CONFLICTS OF INTEREST}

None.

\section{REFERENCES}

1. Maskoen AM, Nasroen SL, Fauziah PN, Soemantri ES, Gani BA. Expression of transforming growth factor alpha Bamhi and Rsai gene variants associated with non-syndromic cleft palate of Indonesian subjects using polymerase chain reaction method. Asian J Pharm Clin Res 2018;11:351-4.

2. Law RC, de Klerk C. Anaesthesia for Cleft and Palate Surgery. UK: Update in Anaesthesia; 2002.

3. Nargozian C. The airway in patients with craniofacial abnormalities. Paediatr Anaesth 2004;14:53-9.

4. Hatch DJ. Airway management in cleft lip and palate surgery. Br J Anaesth 1996;76:755-6.

5. Gunawardana RH, Gunasekara SW, Weerasinghe JU. Anesthesia and surgery in pediatric patients with low hemoglobin values. Indian J Pediatr 1999;66:523-6.

6. Takemura H, Yasumoto K, Toi T, Hosoyamada A. Correlation of cleft type with incidence of perioperative respiratory complications in infants with cleft lip and palate. Paediatr Anaesth 2002;12:585-8.

7. Todd NW, Holt PJ, Allen AT. Safety of neck rotation for ear surgery in children with down syndrome. Laryngoscope 2000;110:1442-5.

8. Gunawardana RH. Difficult laryngoscopy in cleft lip and palate surgery. Br J Anaesth 1996;76:757-9.

9. Gupta S, Sharma R, Jain D. Airway assessment: Predictors of difficult 
airway. Indian J Anaesth 2005;49:257-62.

10. Cormack RS, Lehane J. Difficult tracheal intubation in obstetrics. Anaesthesia 1984;39:1105-11.

11. Bosenberg AT, Madaree A, Osborn I, Bill P. Malignant hyperthermia associated with cleft palate, clubfoot and myopathy. Paediatr Anaesth 2002;12:92.

12. Xue FS, Zhang GH, Li P, Sun HT, Li CW, Liu KP, et al. The clinical observation of difficult laryngoscopy and difficult intubation in infants with cleft lip and palate. Paediatr Anaesth 2006;16:283-9.

13. Mc Donald DS, McCormick A, Mackersie AM. Difficulty with a preformed tube in a neonate. Paediatr Anaesth 1997;7:87.

14. Doyle E, Hudson I. Anaesthesia for primary repair of cleft lip and palate: A review of 244 procedures. Paediatr Anaesth 1992;2:139-45.

15. Steinmetz J, Holm-Knudsen R, Sørensen MK, Eriksen K, Rasmussen LS. Hemodynamic differences between propofolremifentanil and sevoflurane anesthesia for repair of cleft lip and palate in infants. Paediatr Anaesth 2007;17:32-7.

16. Bell C, Oh TH, Loeffler JR. Massive macroglossia and airway obstruction after cleft palate repair. Anesth Analg 1988;67:71-4.

17. Dell'Oste C, Savron F, Pelizzo G, Sarti A. Acute airway obstruction in an infant with pierre robin syndrome after palatoplasty. Acta
Anaesthesiol Scand 2004;48:787-9.

18. Flemming DC, Cooperman LH. Complications in Anaesthesiology. $2^{\text {nd }}$ ed. Philadelphia, PA: JB Lippincott Co.; 1983

19. Szekely SM, Webb RK, Williamson JA, Russell WJ. The Australian incident monitoring study. Problems related to the endotracheal tube: An analysis of 2000 incident reports. Anaesth Intensive Care $1993 ; 21: 611-6$.

20. Gaiser RR. Teaching airway management skills. How and what to learn and teach. Crit Care Clin 2000;16:515-25.

21. Henriksson TG, Skoog VT. Identification of children at high anaesthetic risk at the time of primary palatoplasty. Scand J Plast Reconstr Surg Hand Surg 2001;35:177-82.

22. Xue FS, An G, Tong SY, Liao X, Liu JH, Luo LK, et al. Influence of surgical technique on early postoperative hypoxaemia in children undergoing elective palatoplasty. Br J Anaesth 1998;80:447-51.

23. Valnicek SM, Zuker RM, Halpern LM, Roy WL. Perioperative complications of superior pharyngeal flap surgery in children. Plast Reconstr Surg 1994;93:954-8.

24. Merry AF, Cooper JB, Soyannwo O, Wilson IH, Eichhorn JH. International standards for a safe practice of anesthesia 2010. Can J Anaesth 2010;57:1027-34. 